\title{
Histo-Anatomic Aspects on Zea Mays L. Influenced by Hemp Shives Polyphenolic Extract
}

\author{
Corneliu TANASE*, Sanda COȘARCĂ, Silvia OROIAN \\ Faculty of Pharmacy, University of Medicine and Pharmacy, Gheorghe Marinescu, 38, 540139, Tîrgu \\ Mureș, Mureș, Romania \\ * corresponding author: tanase.corneliu@yahoo.com
}

Bulletin UASVM series Agriculture 73(2)/2016

Print ISSN 1843-5246; Electronic ISSN 1843-5386

DOI 10.15835/buasvmcn-agr: 12426

\begin{abstract}
The plant kingdom is an inexhaustible source of bioactive compounds with antioxidant character. It is known that, natural polyphenols are essential compounds in stimulating plant growth and development. The aim of this study was to identify the internal structure changes in maize (Zea mays L.) seedlings, under the influence of hemp shives polyphenolic extract. Hemp shives polyphenolic extract was characterized in terms of the total content of polyphenols and individual content by HPLC. Germination tests were carried out going through a standard procedure. In order to perform the histo-anatomical characterization, the vegetal material was fixed and preserved in alcohol $70 \%$, following to be cut by hand microtome. The sections obtained were stained using double staining reagents: green - iodine and ruthenium red. It was observed, compared with the control, that hemp shives polyphenolic extract determines a good development of the root hairs and increase leading bundles number and central vessels metaxylem. Hemp shives polyphenolic extract in lower concentrations has positive effects on developed process of Zea mays L. plants that can be attributed to bioregulation properties.
\end{abstract}

Keywords: hemp shives, histo-anatomic, polyphenolic extract, Zea mays L.

\section{INTRODUCTION}

Maize is ranked third after wheat and rice among the most important cereal crops. Maize is essential for human and live-stocks consumption as a major source of carbohydrates, oil or as a protein source. Maize is widely grown as cereal crop in many developing countries including Romania (Jans et al., 2010).

The hemp shives are wastes resulted after bast fibers separation of the Cannabis sativa plant species that is grown specifically for the industrial uses of its derived products. It is one of the fastest growing plants. It can be refined into a variety of commercial items including paper, textiles, clothing, biodegradable plastics, paint, insulation, biofuel, food, and animal feed (Keller, 2013). The outside of the hemp stalk is covered with epidermis, underneath it there are bast fibres whereas in the centre the stem there is a woodpulp core (shive), the proportion of which in the hemp is between 60 to $80 \%$ of the total mass of the stem. The main chemical components of the shive like in spruce wood are cellulose (34-48\%), hemicellulose (21-37\%) and lignin (16-28\%). The difference in chemical composition is determined by the variety, the soil type, the climate conditions (Jaraboa et al., 2012; Troëdec et al., 2009; Troëdec et al., 2011).

Phenolic compounds are secondary metabolites. They are one of the most numerous and widely distributed group of aromatic compounds in the plant kingdom, with over 8000 phenolic structures currently known, of which more than 6000 are the flavonoids (Tsao, 2010; Knezevic et al., 2012). Polyphenols are natural compounds with aromatic structures containing one or more aromatic rings with or without the vicinity of a heterocycle and which are grafted with hydroxyl, carboxyl, methoxyl and carbonyl functional groups. According to the basic chemical structure, 
polyphenols can be classified into more different classes (Garcia Salas et al., 2010). However, two main groups of polyphenols can be identified: flavonoids and nonflavonoids.

Phenolic compounds are considered the most abundant constituents of plants and processed foods; some compounds are extremely widespread while others are specific of certain plant families or found only in some plant organs or at certain development stages. Main sources of phenolic compounds are fruits and vegetables, seeds, cereals, berries, beverages (wine, tea and juices), olive and aromatic plants (Sikora et al., 2008). In last years many studies focused a special attention to the presence of these compounds in agricultural and industrial wastes, wood and nonwood forest resources (Moure et al., 2001; Ignat et al., 2009, 2011; Stingu et al., 2009 a and b; Tanase et al., 2013 a and b, 2014a, 2016; Volf and Popa, 2004; Volf et al., 2006). Natural polyphenols have a broad spectrum of regulating action in plants, tissues and organs, interfering in the metabolic processes (Biesalski et al., 2009; Kris-Etherton et al., 2002; Tomas-Barberan et al., 2000; Tringali, 2001; Zhang et al., 2009). The stimulation or inhibition abilities of natural polyphenols in plant growth and development are closely correlated with the concentrations of these compounds. Thus, in some cases the presence of these compounds in low concentrations can have a beneficial effect on plant's development and in other cases, when concentrations are higher there is an inhibition phenomenon (Popa et al., 2007). Increasing interest in the replacement of synthetic growth regulators (Sairam, 1994) has led to a search into natural sources of regulator agents.

The study of the polyphenolic compounds effect on the level of living systems, presents a special scientific interest. Through, it has been established that these compounds have many effects on living systems, such as: antioxidant, immunostimulating, antimutagen, antibacterial, bioregulator. In previous work (Tanase et al., 2016) we found that the aqueous extract obtained from the spruce bark determines a good development of root hair, vascular bundles and metaxylem vessels. It was observed that at higher concentration of the extract root hairs are more reduced and the process of lignification is more intense compared to the control. Therefore, it was found that bioactive compounds existing in hemp shives aqueous extracts can modulate the bioaccumulation process of lead and copper ions in Brassica napus. At low concentrations in soil the presence of hemp shives stimulates lead and copper bioaccumulation, promoting the translocation of heavy metals to the aerial part of the plant. In this case the polyphenolic compounds from hemp shives increase the solubilisation of heavy metals and improve the phytoextraction process (Tanase et al., 2014b). The present research is concerned with the use of the wastes from the industrial hemp, Cannabis sativa $\mathrm{L}$., to obtain polyphenolic extract and to identify the internal structure changes in maize (Zea mays L.) seedlings, under the influence of hemp shives polyphenolic extract.

\section{MATERIALS AND METHODS}

The hemp shives used in this study are wastes resulted after bast fibers separation. The vegetal material was randomly collected, while the species was identified and authenticated. The vegetal material was shade-dried at room temperature for two weeks, a reference sample (blank) being kept for comparison. For chemical characterization, 20 grams of ground dried material with particle size of $0.5-1 \mathrm{~mm}$ were extracted consecutively for three times with $125 \mathrm{~mL}$ distilled water on a water bath, for 45 minutes, at $80^{\circ} \mathrm{C}$, and finally, the extracts were cumulated to a final volume of $500 \mathrm{~mL}$ using distilled water. Dry matter content in the extracts was determined by evaporation of $25 \mathrm{~mL}$ extract on water bath and drying at $105^{\circ} \mathrm{C}$, until a constant mass is reached. After that the crucible containing the dry matter was placed into a furnace at $600^{\circ} \mathrm{C}$, in order to establish the mineral and organic matter content. Folin Ciocalteu (FC) method was used to determine the total polyphenolic content (TPC) in aqueous extract and the concentrations were expressed as the number of equivalents of gallic acid (GAE) (Bao et al. 2005; Ignat et al. 2011). For the HPLC analysis, the cumulated aqueous extracts were concentrated under vacuum to 10 $\mathrm{mL}$. These results as well as the extraction method were published in our previous work (Tanase et al., 2014b).

Maize seeds were purchased from Unisem Company, Romania. Germination tests were carried out going through a standard procedure, using increments of 10 Petri dishes for each solution studied. On a filter paper were placed 
every five maize seeds, carefully selected without present any major damage. For starters, the vegetal material has undergone a presterilization process, which consisted of submerged seed in absolute ethanol for 10 seconds, following the sterilization in the presence of sodium hypochlorite $10 \%$ for 20-30 minutes (Cachița et al., 2004). The volume of hemp shives polyphenolic solution added was $10 \mathrm{~mL} /$ dishes meanwhile for the reference samples distilled water was used. Petri dishes thus prepared were incubated in the dark in a thermostat set at $28 \stackrel{\circ}{\circ}$. After a period of seven days Petri dishes were taken out and the roots, stems and leaves separated for histo-anatomic analysis. In order to perform the histo-anatomical characterization, the vegetal material was fixed and preserved in alcohol $70 \%$, following to be cut by hand microtome with botanical razor (Tanase et al., 2016). First, were performed cross sections, using botanical razor, hand microtome and marrow elderberry through the vegetative organs of plants and seedlings. Obtained sections were collected on a watch glass with water. The sections obtained were stained using double staining reagents: green - iodine and ruthenium red. After removing water from the glass plate, the sections were stained for several tens of seconds (with a few drops of methylene blue) or 1 minute (with a few drops of iodine green). After removing the dye, the sections were washed with $70 \%$ ethanol and then once with tap water and were then stained for several tens of seconds ruthenium red and subsequently washed twice with tap water. Subsequently stained sections were mounted between slide and slide in a few drops of water and analyzed with a microscope Novex (Holland) and photographed with Nikon Coolpix L22 (Tanase et al., 2016).
All the results are expressed as mean \pm standard error where $n=3$. Comparison of the means was performed by the Fisher least significant difference (LSD) test ( $p \leq 0.05)$ after ANOVA analysis using program PAST 2.17c. Sampling and chemical analyses were examined in triplicate, in order to decrease the experimental errors and to increase the experimental reproducibility.

\section{RESULTS AND DISCUSSION}

The characterization of hemp shives extract was made in a past work (Tanase et al., 2014b). Thus, the total polyphenols content of hemp shives aqueous extract was $164 \mathrm{mg}$ GAE/100g. The chromatographic analysis reveald: catechins (5.21 g/100g plant material), caffeic acid (9.68 $\mathrm{g} / 100 \mathrm{~g}), \mathrm{P}$ - coumaric acid and ferulic acid in reduced quantites.

To highlight the effect of hemp shives polyphenolic extract, some histo-anatomical aspects of the internal structure of maize seedlings were analysed. Thus, in this paper, histo-anatomical aspects, regarding the internal structure of primary roots, adventitious roots, mesocotyl, epicotyl and leaves will be presented.

At the root level (Fig. 1. b), the root hairs are larger and many compared to the control (Fig. 1. a). Exoderma is only sketched, having larger cells compared to the endoderm. In cortical parenchyma are numerous aeriferos cavities with different size and radial elongated. Endodermis cells present the primary stage (thickening Caspary) and few of them show the inner wall thickened. The number of conductive vascular bundles is higher (8), all surrounded by a unsclerified and unlignified parenchym. Medullary parenchym is noticeably lower than the control.
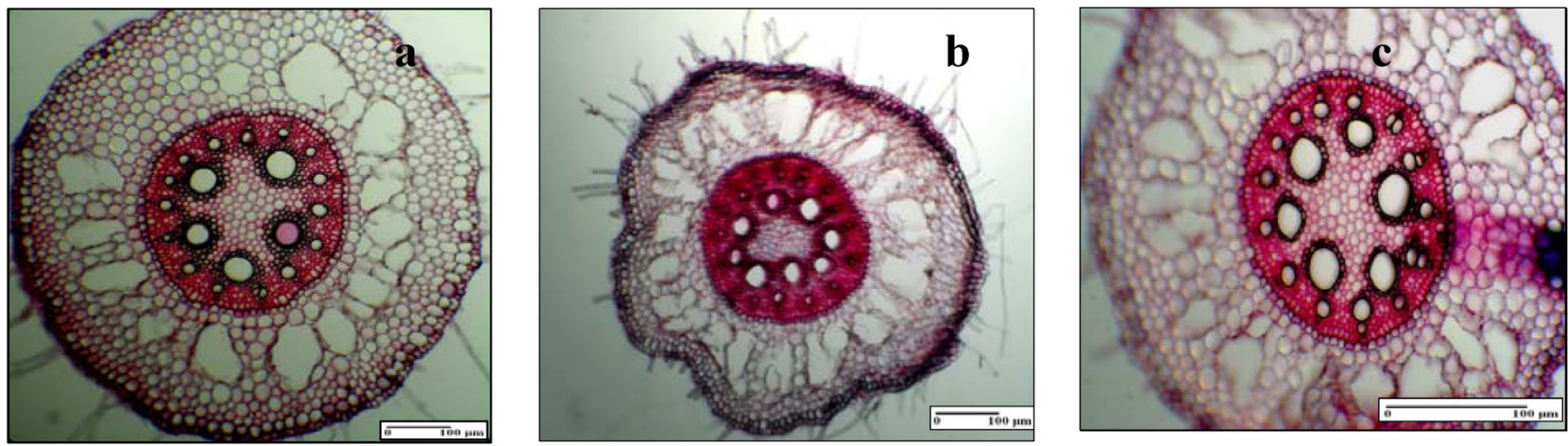

Fig. 1. The internal structure of the main root, a. general aspect (control), b. general aspect (P2), c. detail-P1 (pith, central cylinder, cortex, rizodermis) 

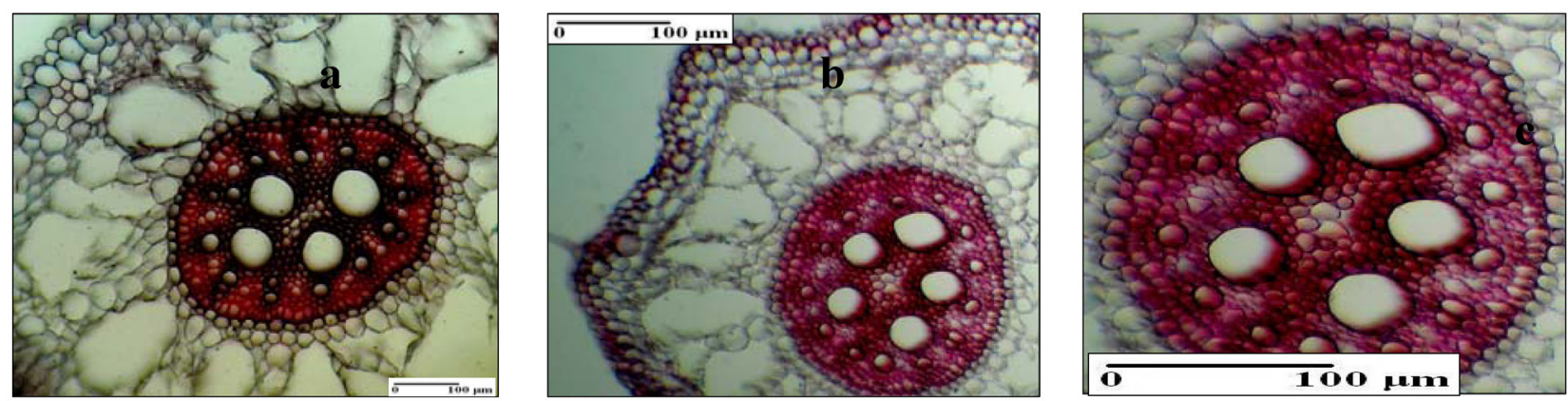

Fig. 2. The internal structure of adventious roots, a. general aspect (control), b. general aspect (P2), c. central cylinder (P2)
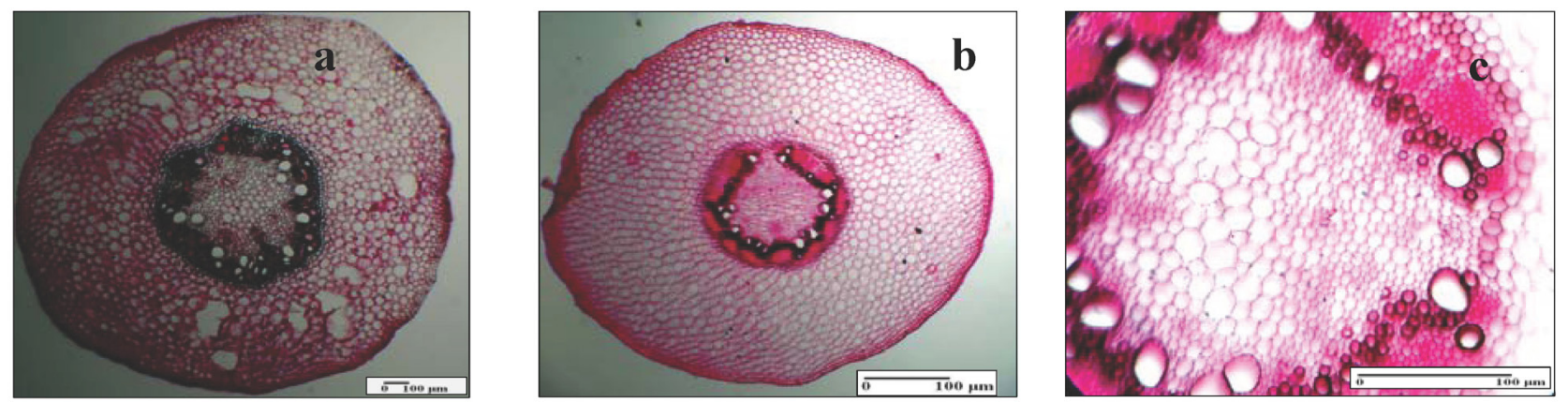

Fig. 3. The internal structure of mesocotyl, a. general aspect (control), b. general aspect (P2), c. central cylinder (P2)

At a higher concentration (233 mg GAE/ L) is observed (Fig. 1.c) that endoderm is in the transition stage from primary to tertiary type. The number of xylem bundles, as well as the phloem bundles is smaller comparing with control (14 xylem, 14 phloem). The number of central vessels of metaxylem is 6 , all surrounded by a layer of lignified parenchyma cells. Lignification process was noticed to be more intense, both in xylem vessels and in the central vessels metaxylem parenchyma. On some sections was observed the formation of lateral roots endogenously.

Adventitious roots (Fig. 2. b) present frequent and long root hairs, with only sketched exoderma consists of cellulose walls. The endoderm is in the primary type. Aeriferous cavities in the cortical parenchyma are large and often many times next to each other separated only by a series of radial parenchyma cells with a moderate sclerified pericycle. The number of vascular bundles is higher comparing with control (14) and central metaxilem vessels (5) are arranged in a circle (Fig. 2. b, c). At a higher concentration (233 mg / L) root hairs are very rare or absent and exoderma is without suber. The cortical parenchyma includes many aeriferous cavities and endoderm is in the primary type same like P2 variant. The number of vascular bundles is higher compared to the control (13 xylem, 13 phloem) as that of the central vessels metaxilem (6) each surrounded by a layer of lignified parenchyma cells.

The coleoptile (Fig. 4.b, c) has mesophil from the two poles, much thicker than the sides, which is often reduced to only two epidermis. The aeriferous cavities of mesophylic missing. The two vascular bundles (Fig. 4. b, c) are typically collateral closed (the phloem being partially surrounded by xylem vessels) and are less developed compared to the control (Fig. 4.a). At a higher concentrations (P1), the thickness of coleoptyle at the two poles of the section is slightly greater than the sides. The external epidermis cells are visible radial elongated and are much larger than the interior epidermis. Aeriferous cavities of mesophyll are missing and the two driving vascular bundles are structurally similar to those of P2 version, always the phoem is more abundant than xylem. In case of leaf (fig. 5. b and c) groups of buliphorm cells on 

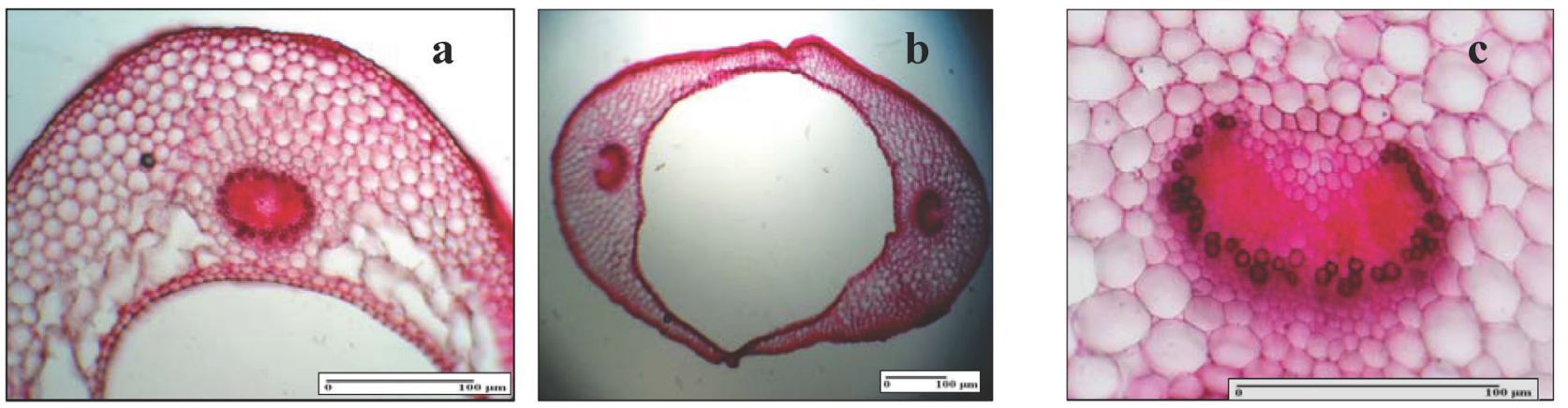

Fig. 4. The internal structure of coleoptile, a. general aspect (control), b. general aspect (P2), c. vascular bundle (P2)
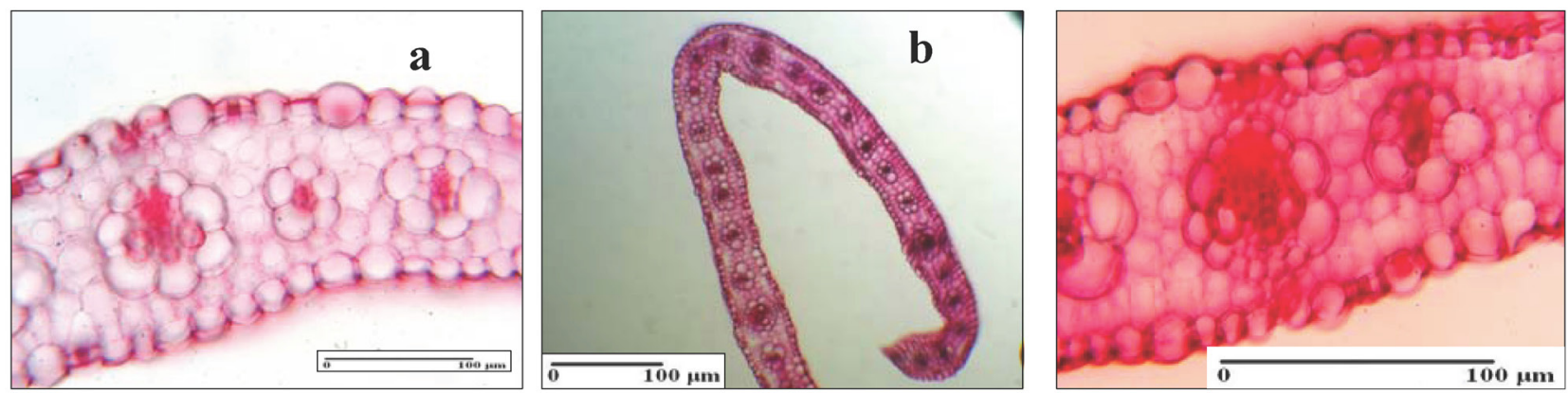

Fig. 5. The internal structure of foliar blade, a. general aspect (control), b. the internal structure of foliar blade - general aspect (P2), c. the internal structure of foliar blade - vascular bundles (P2)

upper epidermis can be observed.

The cells from mesophilic hypoderm are slightly elongated radial on both sides of the leaf lamina. To the edge of the limb, mesophylic is reduced to 2-3 layers of cells and to the edge are visible only two epidermis. At a higher concentration hypodermic mesophylic has only slightly elongated cells radiate.

\section{CONCLUSIONS}

Analyzing the obtained results we can appreciate that the aqueous extract obtained from the hemp shives determines a good development of root hair, vascular bundles and metaxylem vessels. Addition of the aqueous extract obtained from hemp shives in the growth of maize seedlings leads to a increase in the number of vascular bundles. Their number decreases with increasing concentration of extract applied. In the adventitious roots are less frequent hairs root and exoderma is unsuberified. The mesocotyl has xylem vessels smaller than that of the control. At higher concentration is tertiary type of endoderm.
In the coleoptile xylem is less developed compared to the control.

Hampe shives polyphenolic extract in lower concentrations has positive effects that can be attributed to their antioxidant properties. When the extracts with high concentrations of polyphenols were used, it was found inhibitory effect on the growth and development of plant systems. The results recorded in this study confirm some of the previously hypotheses and open research in the field.

Acknowledgements: This work was supported by the University of Medicine and Pharmacy of Tîrgu Mureș Research Grant number 17800/3/22.12.2015.

\section{REFERENCES}

1. Bao JS, Cai Y, Sun M, Wang GY, Corke H (2005). Anthocyanins flavonols and freeradical scavenging activity of Chinese bayberry (Myrica rubra) extracts and theircolor properties and stability. J. Agric. Food Chem. 53:2327-2332.

2. Biesalski H, Dragsted LO, Elmadfa I, Grossklaus R, Muller M, Schrenk D, Weber P (2009). Bioactive compounds: 
definition and assessment of activity. Nutrition, 25:12021205.

3. Cachiță-Cosma D, Deliu C, Rakosz-Tican L., Ardelean A (2004). Treaty of plant biotechnology, Ed Dacia, Cluj Napoca 84-89.

4. Garcia-Salas P, Morales-Soto A, Segura-Carretero A (2010) Phenolic-Compound-Extraction Systems for Fruit and Vegetable Samples Molecules, 15(12):8813-8825.

5. Ignat I, Stângu A, Volf I, Popa IV (2009). Natural bioactive compounds as plant growth regulators, Scientific Papers, Series Agronomy, Iaşi, 52:78-85.

6. Ignat I, Stingu A, Volf I, Popa VI (2011). Characterization of grape seed aqueous extract and possible applications in biological systems, Cellulose Chemistry and Technology, 45(3-4):205-209.

7. Jans WP, Jacobs Kruijt MJ, Elbers AJ, Barendse S, Moors E] (2010). Carbon exchange of a maize (Zea mays L.) crop: Influence of phenology, Agric. Eco. Env., 139: 316.

8. Jaraboa R, Fuentea E, Montea MC, Savastano H, Mutjéc J, Negroa C (2012). Use of cellulose fibers from hemp core in fiber-cement production. Effect on flocculation, retention, drainage and product properties, Ind. Crop. and Prod. 39:89-96

9. Keller NM (2013). The legalization of industrial hemp and what it could mean for indiana's biofuel industry, Ind. Inter. \& Comp. Law Review 23(3):555.

10. Kris-Etherton P, Hecker K, Bonanome A, Coval S, Binkoski A, Hilpert K, Griel A, Etherton T (2002). Bioactive compounds in foods: their role in the preventionof cardiovascular disease and cancer. American Journal of Medicine, 113(9):71-88.

11. Moure A, Cruz JM, Franco D, Dominguez JM, Dominguez H, Jose Nunez M, Parajo C (2001). Natural antioxidants from residual sources, Food. Chem. 72:145-171.

12. Popa VI, Danailă M, Volf I, Popa M (2007). Natural polyphenolic compounds. Structure, bioavailability and microbial interactions. In Proceedings of $8^{\text {th }}$ Forum of International Lignin Institute, Rome, 89-90.

13. Sairam RK (1994). Effect of homobrassinolide application on metabolism and grainyield under irrigated and moisture stress conditions of two wheat varieties.Plant Growth Regulators, 14:173-181.

14. Sikora E, Cieslik E, Topolska K (2008). The sources of natural antioxidants, Acta Sci. Pol., Technol. Aliment., 7:57.

15. Stingu A, Volf I, Popa IV (2009a). Chestnuts (Castanaea sativa), extracts - a potential plant growth regulator, Bulletin of the Polytechnic Institute, Iasi, 69-77, (2009).

16. Stingu A, Volf I, Popa VI (2009b). Physiological changes in seedling germination and growth plant under chemical stress conditions, Environ. Eng. Manag. J. 6:1309-1313.
17. Tanase C, Volf I, Popa IV (2013a). Assessment of the synergic regulator action of spruce bark extract and deuterium depleted water on maize (Zea mays L.) crops. Environ. Eng. Manag. J. 12 (6):1287-1294.

18. Tanase C, Vantu S,Volf I, Popa IV (2013b). Potential applications of wastes from energy and forestry industry in plant tissue culture, Cell. Chem. Technol. 47(7-8):553563.

19. Tanase C, Boz I, Popa IV (2014a). Histo-anatomical aspects in maize (Zea mays L.) seedlings developing under influence of deuterium depleted water, Annals of the University "Alexandru Ioan Cuza" University of Iasi (New Series), Vegetal Biology, 60(2): 5-10.

20. Tanase C, Volf I, Popa VI (2014b). Enhancing copper and lead bioaccumulation in rapseed by adding hemp shives as soil natural amendments, J. of Env. Eng. And Land. Manag. 22(04):245-253.

21. Tanase C, Boz I, Popa IV (2016). Histo-anatomical aspects on Zea mays L. influenced by spuce bark polyphenolic extract, Rom. Biotech. Letter. 21(1):11238-11245.

22. Tomas-Barberan FA, Ferreres F, Gil MI (2000). Antioxidant phenolic metabolites from fruit and vegetables and changes during postharvest storage, processing in A. Rahman, Ed. Bioactive natural products (Part D) 739-795.

23. Tringali C (2001). Bioactive Compounds from Natural Sources: Isolation, characterization and biological properties. Taylor \& Francis, London.

24. Troëdec M, Peyratout CS, Smith A, Chotard T (2009). Influence of various chemical treatments on the interactions between hemp fibres and a lime matrix. J. Eur. Ceram. Soc. 29:1861-1868.

25. Troëdec M, Rachini A, Peyratout C, Rossignol S, Max E, Kaftan O, Fery A, Smith A (2011). Influence of chemicaltreatments onadhesionproperties ofhempfibres. J. Colloid Interface Sci. 356:303-310.

26. Tsao R (2010). Chemistry and biochemistry of dietary polyphenols. Nutrients, 2, 1231-1246.

27. Vladimir-Knežević S, Blažeković B, Štefan MB, (2012). Phytochemicals as Nutraceuticals - Global Approaches to Their Role in Nutrition and Health (Venketeshwer R., Ed.), InTech, 155-180.

28. Volf I, Popa IV (2004). The obtaining of active compounds with antioxidant properties from vegetable by-products. Study of the extraction process of polyphenolic compounds from Vitis sp. Wood, Journal of Chemical. 55:707-710.

29. Volf I, Mamaliga I, Popa IV (2006). Active principia with antioxidant character from vegetal by products, Equilibrium study of the polyphenolic compounds extraction from wood Vitis sp., Cellul. Chem. Tech. 40:205209.

30. Zhang Z, Liao L, Moore J, Wua T, Wang Z (2009). Antioxidant phenolic compounds from walnut kernels (Juglans regia L.), Food Chem., 113:160-165. 